\title{
Effect of Gonadectomy and Gonadal Hormone Replacement on Cocaine Self-Administration in Female and Male Rats
}

\author{
S Barak Caine*,', Carrie A Bowen', Gloria Yu', David Zuzga', S Stevens Negus' and Nancy K Mello' \\ 'McLean Hospital, Alcohol and Drug Abuse Research Center, Harvard Medical School, Belmont, MA, USA
}

\begin{abstract}
Both sex and gonadal steroid hormones may influence the abuse-related behavioral effects of cocaine under some conditions, but there is considerable inconsistency in the literature. In the present study, rats were trained under a fixed ratio (FR) 5 schedule of food presentation and were then allowed to self-administer cocaine $(1.0 \mathrm{mg} / \mathrm{kg} / \mathrm{injection})$ until behavior stabilized. Subsequently, complete dose-effect functions for cocaine self-administration $(0.032-3.2 \mathrm{mg} / \mathrm{kg} /$ injection) were determined in female and male rats before and after gonadectomy, and in gonadectomized female and male rats before and during chronic treatment with estradiol or testosterone, respectively. Sex, gonadectomy, and gonadal hormones did not alter the shape or position of dose-effect functions for cocaine selfadministration. These results suggest that sex, estrogen, and testosterone levels are not critical determinants of cocaine's reinforcing effects in rats under these conditions. This study differed from earlier studies in that complete dose-effect functions for cocaine were determined. These findings suggest that the behavioral training history, the unit dose of cocaine, and the schedule of reinforcement are important variables in studies of sex and gonadal hormone effects on cocaine self-administration.
\end{abstract}

Neuropsychopharmacology (2004) 29, 929-942, advance online publication, 2 I January 2004; doi: I 0.I 038/sj.npp. 1300387

Keywords: cocaine; self-administration; estrogen; testosterone; sex; rat

\section{INTRODUCTION}

Several lines of evidence suggest that gonadal steroid hormones may influence the behavioral and abuse-related effects of cocaine (Lynch et al, 2002; Mello and Mendelson, 2002). However, findings from both clinical and preclinical studies have been inconsistent. Relative to men, women have been reported to have both lower and higher subjective and physiological responses to cocaine, and no differences have been detected under some conditions (Lukas et al, 1996; Kosten et al, 1996; Mendelson et al, 1999; Sofuoglu et al, 1999; Evans et al, 2002). In contrast, preclinical studies have consistently suggested sex differences and a modulatory role for estrogen on psychomotor stimulant drug effects. For example, cocaine-induced stimulation of locomotor activity in female rats was enhanced during estrus, and this effect was decreased by ovariectomy (Sell et al, 2000; Zhou et al, 2002). Cocaine also produced greater locomotor activation in ovariectomized rats treated with estrogen than in untreated ovariectomized rats or ovari-

\footnotetext{
*Correspondence: S Barak Caine, McLean Hospital, Harvard Medical School, Alcohol and Drug Abuse Research Center, 115 Mill Street, Belmont, MA 02478, USA, Tel: + I 617855 2258, Fax: + I 617855 3865, E-mail: barak@mclean.harvard.edu

Received 05 June 2003; revised 26 November 2003; accepted 04 December 2003

Online Publication: 16 December 2003 at http://www.acnp.org/ citations/Npp I 2 160303254/default.pdf
}

ectomized rats treated with progesterone (Sell et al, 2000; $\mathrm{Hu}$ and Becker, 2003). Stereotypic as well as locomotor responses to cocaine, amphetamine, and methamphetamine were greater in female rats than in male rats (Schneider and Norton, 1979; Savageau and Beatty, 1981; Camp et al, 1986; Schindler et al, 2002; Schindler and Carmona, 2002), and were greater during estrus than during other stages of the estrous cycle (Becker et al, 1982; Becker and Cha, 1989; Quinones-Jenab et al, 1999; Sell et al, 2002).

Although motor responses to cocaine appear to be more robust in female than in male rodents, no differences in the discriminative stimulus effects of cocaine and amphetamine were found. In rats trained to discriminate 5.6 or $10 \mathrm{mg} / \mathrm{kg}$ of cocaine from saline, there were no sex differences in the potency of cocaine to engender cocaine-appropriate lever responding (Craft and Stratmann, 1996; Anderson and van Haaren, 1999, 2000). No sex differences were found in the dose-dependent substitution of $\mathrm{D}$-amphetamine for cocaine, or in the antagonism of cocaine's discriminative stimulus effects by dopamine antagonists (Craft and Stratmann, 1996; Anderson and van Haaren, 2000).

Intravenous cocaine self-administration may differ between female and male rats, and estradiol may modulate the reinforcing effects of cocaine under some conditions (Roberts et al, 1989; Grimm and See, 1997; Lynch and Carroll, 2000; Lynch et al, 2001; Carroll et al, 2002; Hu et al, 2003). For example, female rats trained to self-administer cocaine under a progressive ratio (PR) schedule achieved 
higher break points than male rats, and break points were higher during estrus than during other phases of the estrous cycle (Roberts et al, 1989; Carroll et al, 2002). When various doses of cocaine were available, female rats chose higher cocaine doses during estrus than during other phases of the estrous cycle (Lynch and Carroll, 2000). Finally, when acquisition of cocaine self-administration was studied with an autoshaping procedure, the acquisition criteria were met by more females than males, and by more gonadally-intact females and ovariectomized females given estrogen replacement than by untreated ovariectomized females or intact females that received an estrogen antagonist (Lynch and Carroll, 1999; Lynch et al, 2001; Carroll et al, 2002). Similar findings were also reported for acquisition of cocaine selfadministration under a fixed ratio (FR) 1 schedule of reinforcement ( $\mathrm{Hu}$ et al, 2003). These findings were interpreted to suggest that estrogen increased the reinforcing effects of cocaine. However, no sex differences were observed when cocaine self-administration was maintained under an FR 1 schedule of reinforcement, and under those conditions, estrous cycle phase in intact rats or estradiol administration to ovariectomized rats did not affect cocaine self-administration (Roberts et al, 1989; Lynch and Carroll, 2000; Cosgrove et al, 2002). Moreover, in ovariectomized rats, chronic estradiol administration did not affect cocaine self-administration maintained under FR or PR schedules of reinforcement, and acute estradiol administration decreased cocaine self-administration under the PR schedule (Grimm and See, 1997).

A number of procedural variables may have contributed to these discrepant findings. One important variable is the unit dose of cocaine available for self-administration. Greater potency or efficacy of cocaine as a reinforcer may be evidenced by leftward or upward shifts in dose-effect functions for cocaine self-administration. As dose-effect functions for cocaine self-administration under fixed-ratio schedules are characterized by an inverted U-shape, curve shifts are most clearly assessed by studying both the ascending and descending limbs of the dose-effect function (Mello and Negus, 1996). One goal of the present study was to determine whether there are differences in the shape and position of complete dose-effect functions for cocaine selfadministration in females and males, and in gonadectomized rats before and during exogenous gonadal hormone administration.

Another important variable that may influence drug selfadministration is operant performance. Although cocaine self-administration behavior was acquired more rapidly by female than by male rats, and by intact and ovariectomized females treated with estradiol than by untreated ovariectomized females (Lynch and Carroll, 1999; Lynch et al, 2001; Carroll et al, 2002; Hu et al, 2003), these results could be due to performance differences in acquisition of operant behavior rather than differences in the reinforcing effects of cocaine. In the present study, rats were operant trained with food reinforcement prior to evaluation of cocaine selfadministration behavior to minimize the influence of performance differences, and possible sex differences in food-maintained behavior were also assessed.

Another goal of the present study was to determine if testosterone modulates cocaine's reinforcing effects in male rats, and to compare the results to the effects of estradiol in females. There has been considerably less research on gonadal hormone influences on cocaine's effects in males than in females, and findings from studies of unconditioned responses are inconsistent. Acute testosterone administration enhanced cocaine-induced hyperactivity under some conditions (Martinez-Sanchez et al, 2002). In contrast, chronic testosterone administration decreased cocaineinduced hyperactivity in intact rats (Long et al, 1994). Moreover, several reports indicated that spontaneous and psychostimulant-induced locomotion, stereotypy, and brain dopamine levels were preserved or even enhanced in castrated rats compared with intact males (van Luijtelaar et al, 1996; Hull et al, 1997; Kuhn et al, 2001; Chin et al, 2002; Sorg et al, 2002). Consistent with these findings, it was recently reported that acquisition of cocaine self-administration did not differ in castrated and sham-operated male rats ( $\mathrm{Hu}$ et al, 2003).

In the first experiment, acquisition of cocaine selfadministration was examined in intact female and male rats, and complete cocaine dose-effect functions were determined under an FR 5 schedule. The effects of varying the concentration of liquid food on food-maintained responding under an FR 5 schedule were also compared in intact female and male rats. After cocaine self-administration was acquired, rats were gonadectomized or shamoperated, and complete cocaine dose-effect functions were redetermined. In the second experiment, gonadectomized females and males were trained to self-administer cocaine, and complete cocaine dose-effect functions were determined under an FR 5 schedule. Subsequently, estradiol or testosterone pellets were implanted subcutaneously in females and males, respectively, and complete cocaine dose-effect functions were redetermined. Control studies were conducted to establish that circulating concentrations of estradiol and testosterone were depleted by gonadectomy and restored to physiologic levels by hormone pellet implantation.

\section{METHODS}

\section{Subjects}

Experimentally näive adult Sprague-Dawley female $(n=58)$ and male $(n=62)$ rats were obtained from Charles River Laboratories (Wilmington, MA) at approximately 8-10 weeks of age and weighing approximately 220 and $280 \mathrm{~g}$, respectively. All rats were acclimated to clear Plexiglas cages with bedding in a temperature- and humidity-controlled room with a 12-h light/dark cycle (lights on at 0700) for a minimum of 1 week. During this time, food (PMI LabDiet Rat Diet 5012, Farmer's Exchange, Framingham) and water were freely available, and animals were handled by an experimenter on at least three separate occasions. Thereafter, all rats were given approximately $14.5 \mathrm{~g}$ of food per day in the home cage. Approximately half of the animals were assigned to behavioral experiments and the other half to endocrine experiments. Initially, most of the rats were group housed, and some were individually housed. All rats were individually housed after surgical manipulations (see below).

Animal maintenance and research were conducted in accordance with the guidelines provided by the Committee 
on Care and Use of Laboratory Animals of the Institute of Laboratory Animal Resources, National Research Council. All research protocols were approved by the McLean Hospital Institutional Animal Care and Use Committee. The health of rats was monitored daily by experimenters and periodically by a consultant veterinarian.

\section{Behavioral and Surgical Procedures}

An overall summary of behavioral procedures, including sequence of training and testing, is shown schematically in Table 1. Details are provided below.

Operant apparatus. Operant behavioral training and testing were conducted in sound-attenuating and ventilated operant chambers $\left(21 \times 29.5 \times 24.5 \mathrm{~cm}^{3}\right.$; Med Associates Inc., Georgia, VT). Two response levers were located on either side of a centrally located food receptacle (the 'front' levers), and one lever was located in the center of the opposite wall (the 'rear' lever). Levers were $4 \mathrm{~cm}$ wide and located $3 \mathrm{~cm}$ from the floor. A stimulus light was located above each lever. A pellet dispenser (ENV-203, Med Associates, Georgia, VT) delivered $45 \mathrm{mg}$ food pellets (PJ Noyes, Lancaster, $\mathrm{NH}$ ) into the food receptacle. Cocaine was delivered intravenously with infusion pumps (PHM-100, Med Associates, Georgia, VT) equipped with $3.3 \mathrm{rpm}$ motors and connected to a single channel liquid swivel (Lomir Biomedical, Malone, NY) with spring-reinforced connector tubing. Scheduling of experimental events and data acquisition were accomplished with computers located in an adjoining room.
Training procedure with food pellet reinforcement. Following acclimation to the laboratory, lever-pressing behavior was shaped with food reinforcement during training sessions conducted 5 days per week. Food-training sessions lasted for $1 \mathrm{~h}$ or until 100 food pellets were delivered, whichever occurred first. Initially, stimulus lights were illuminated over each of the three levers in the operant chamber, and a single response on any of the levers resulted in delivery of a food pellet and initiation of a $20 \mathrm{~s}$ timeout period, during which all stimulus lights were turned off and responding had no scheduled consequences (FR 1 TO 20-s schedule of reinforcement). Once a rat earned $>30$ pellets in a single session, the schedule conditions were changed so that food pellet delivery was contingent upon responding only on the rear lever, and responding on either of the two front levers had no scheduled consequences. The response requirement on the rear lever was gradually increased to an FR 5, and food training was considered complete when a rat earned $>30$ pellets under the FR 5 schedule during a single session.

Liquid food reinforcement procedure. Following food training with food pellet reinforcement, responding maintained under an FR 5 schedule of liquid food presentation was evaluated in groups of female and male rats $(n=10)$. The procedure was identical to the FR 5 schedule of food pellet reinforcement except that sessions lasted up to $2 \mathrm{~h}$ and completion of the response requirement resulted in delivery of $75 \mu \mathrm{l}$ of vanilla-flavored Ensure (a nutritional supplement; Abbott Laboratories, Columbus, OH). After responding stabilized (see criteria above), responding was

Table I Sequence of Training and Testing Procedures

\begin{tabular}{lll}
\hline Operant task, listed chronologically & Criteria for completion & Experimental $^{\text {groups }} \mathbf{b}^{\mathbf{b}}$ \\
\hline FR I food maintained responding & 30 reinforcers earned per $\mathrm{h}$ & Males and females $(n=26$ per sex $)$ \\
FR 3 food maintained responding & Same as above & Same as above \\
FR 5 food maintained responding & Same as above & Same as above \\
& & Control studies: liquid-food maintained responding in \\
& & males and females $(n=10)$
\end{tabular}

FR 5 cocaine IVSA (acquisition)

FR 5 cocaine IVSA (dose-effect)

FR 5 cocaine IVSA (dose-effect) $\geqslant 5.0 \mathrm{mg} / \mathrm{kg} / \mathrm{h}$ and $\leqslant 10 \%$ variation for three sessions

All doses tested at least twice

All doses tested at least twice

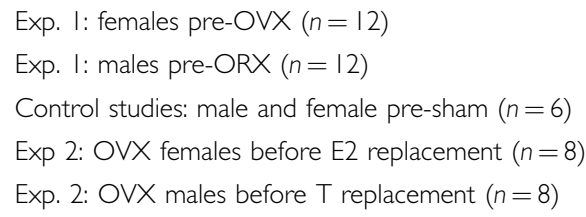

All of the above

Exp. I: females post-OVX $(n=12)$

Exp. I: males post-ORX $(n=12)$

Control studies: male and female post-sham $(n=6)$

Exp 2: OVX females during E2 replacement $(n=8)$

Exp. 2: OVX males during $T$ replacement $(n=8)$

aVSA, intravenous self-administration; acquisition, $1.0 \mathrm{mg} / \mathrm{kg} /$ injection cocaine; dose-effect, between-sessions tests with saline or $0.032,0.10,0.32,1.0,3.2 \mathrm{mg} / \mathrm{kg} /$ injection cocaine, using Latin square design.

bOVX, ovariectomized; ORX, orchidectomized; E2, estradiol; T, testosterone. 
reinforced either by water or Ensure for five sessions to allow for extinction of responding in the absence of food presentation. Thereafter, responding maintained by various concentrations of liquid food was evaluated to assess general operant performance across a range of reinforcer magnitudes. Concentrations of liquid food (water, 3, 10, $32 \%$ Ensure in water, or $100 \%$ Ensure) were presented according to a Latin square design, and all concentrations were tested in each rat at least twice.

Intravenous catheter implantation. Following food training, a chronic indwelling intravenous jugular catheter was implanted in each rat using aseptic procedures. Midazolam $(5 \mathrm{mg} / \mathrm{kg}$, i.p.) was administered as a preanesthetic. Anesthesia was maintained during the surgical procedure via an inhaled isoflurane-oxygen vapor mixture. One skin incision was made lateral and anterior to the heart on the ventral surface, and another in the midscapular region on the dorsal surface. Via a trochar, the catheter was threaded subcutaneously with the external port exiting the midscapular region and the tip of the catheter positioned for insertion into the right external jugular vein (for details, see, Caine et al, 1993). The surface muscle and fascia were dissected bluntly to expose the vein. A small cut was made in the vein with artery scissors to allow insertion of a catheter introducer, followed by the catheter. The catheter was secured by sutures tied gently around the catheter within the vein. Upon completion of the surgery, a topical antibiotic ointment was applied at the wound sites, and buprenorphine $(0.032 \mathrm{mg} / \mathrm{kg}$ s.c.) was administered as a postoperative analgesic. In addition, ticarcillin (approximately $20 \mathrm{mg} / \mathrm{kg}$, i.v.) was administered after surgery and once daily for a minimum of five additional days in a solution of heparin and saline (30 USP U heparin $/ \mathrm{ml} 0.9 \%$ saline). Thereafter, catheters were flushed once or twice daily with the solution of heparin and saline (without ticarcillin). Approximately 1 week after surgery, one group of eight rats was allowed to respond for food presentation under an FR 5 schedule until response rates were stable to assess the degree to which surgical procedure disrupted operant responding. Data from these rats indicated that the surgical procedure did not disrupt operant responding (data not shown). As a result, cocaine self-administration was initiated immediately following the surgery recovery period for all remaining rats in the study.

Cocaine self-administration procedure. During initial selfadministration training, cocaine $(1.0 \mathrm{mg} / \mathrm{kg} / \mathrm{injection})$ was available under an FR 5 TO 20-s schedule of reinforcement on the rear lever during $3 \mathrm{~h}$ sessions, 5 days per week. The concentration of cocaine was $5.6 \mathrm{mg} / \mathrm{ml}$ and the cocaine unit dose was adjusted for each subject's body weight by adjusting the infusion volumes and durations. For example, for a rat that weighed $320 \mathrm{~g}, 0.056 \mathrm{ml}$ of the $5.6 \mathrm{mg} / \mathrm{ml}$ cocaine solution was delivered intravenously over $3.2 \mathrm{~s}$. If a subject self-administered fewer than 10 cocaine injections in a $3 \mathrm{~h}$ session, the response requirement was reset to FR 1 in the next training session, and incremented (FR 3, FR 5) after the subject earned at least 10 cocaine injections during a subsequent session. Criteria for acquisition of cocaine selfadministration were: (a) a minimum of $5.0 \mathrm{mg} / \mathrm{kg}$ self- administered during each hour of the 3-h session, and (b) stable levels of drug intake $( \pm 10 \%)$ for three consecutive sessions. These criteria for baseline were selected for two reasons. First, stable drug intake for three consecutive sessions $( \pm 10 \%)$ is a standard criterion for stable selfadministration of cocaine within this dose range (Caine et al, 1993). Second, in this study (and others with similar conditions), self-administration of fewer than five injections per hour of $1.0 \mathrm{mg} / \mathrm{kg} /$ injection led to increasing or decreasing trends in subsequent sessions within a subject (unpublished observations).

When a subject met criteria for acquisition of cocaine self-administration, saline was substituted for cocaine $(1.0 \mathrm{mg} / \mathrm{kg} /$ injection $)$ in every other session until saline self-administration was tested three times. Thereafter, doseeffect functions for cocaine self-administration were determined by substituting saline or various unit doses of cocaine $(0.032,0.1,0.32,1.0$, or $3.2 \mathrm{mg} / \mathrm{kg} /$ injection) in consecutive sessions. The starting dose was balanced across rats based on a Latin square design. The unit dose of cocaine was varied by changing the concentration of the cocaine solution by one-half log-unit increments $(0.18,0.56$, $1.8,5.6,18.0 \mathrm{mg} / \mathrm{ml})$, and the infusion volume and duration were adjusted based on each subject's body weight (see above). Cocaine dose-effect test sessions terminated after $3 \mathrm{~h}$ had elapsed or after the delivery of 100 injections (whichever occurred first). The cocaine self-administration dose-effect function was determined twice under each experimental condition. Double determinations for each animal were averaged, and those values were used to calculate group means and standard errors. In the event of catheter failure, testing was interrupted to allow for surgical implantation of a second catheter into the left jugular vein, as described above. After recovery from surgery, selfadministration of the training dose of cocaine $(1.0 \mathrm{mg} / \mathrm{kg} /$ injection) was evaluated first, and then dose-effect testing was resumed. Whenever self-administration of $1.0 \mathrm{mg} / \mathrm{kg} /$ injection of cocaine deviated from baseline parameters $( \pm 10 \%$ of the previous determination with $1.0 \mathrm{mg} / \mathrm{kg} /$ injection), tests with this dose of cocaine were conducted until a return to the previous baseline was observed or until a new baseline was established (using the same baseline criteria for initial acquisition).

Ovariectomy, orchidectomy, and sham surgeries. Rats were anesthetized with midazolam $(5.0 \mathrm{mg} / \mathrm{kg}$, i.p.) and an isoflurane-oxygen vapor mixture, and one of the following surgical procedures was performed: bilateral ovariectomy $(n=20)$, sham ovariectomy $(n=6)$, bilateral orchidectomy $(n=20)$, or sham orchidectomy $(n=6)$. Ovariectomy consisted of a single dorsal transverse incision (1.0$1.5 \mathrm{~cm}$ ), including the area ventral to the epaxial muscles around the third lumbar vertebrae and caudal to the last rib. The subcutaneous tissues and abdominal wall muscles were separated. The peritoneum was punctured approximately $5 \mathrm{~mm}$ off midline to reveal and allow extraction of the ovaries. Orchidectomy consisted of a single ventral transverse incision $(1.0-1.5 \mathrm{~cm})$. The subcutaneous tissues were separated to expose the linea alba. A stab incision was made through the linea alba and enlarged to reveal and allow extraction of the testes. After bilateral removal of the 
gonads, the body wall was closed with sutures, and the skin was closed with surgical glue Vetbond $^{\mathrm{R}}, 3 \mathrm{M}$ Animal Care Products, Minneapolis, MN). The sham surgeries involved anesthetizing the animal and making an incision, but the gonads were not removed. All wounds were treated with antibiotic ointment, and buprenorphine $(0.032 \mathrm{mg} / \mathrm{kg}$, s.c.) was administered as a postoperative analgesic.

All animals were allowed to recover for 2 weeks after gonadectomy or sham surgery, because previous research indicates that 2 weeks is required for stabilization of gonadal and pituitary hormones after gonadectomy (Peris et al, 1991). For animals with indwelling catheters, the catheter was flushed up to twice daily with a solution of heparin and saline ( $30 \mathrm{U}$ heparin/ml saline) to maintain patency. At 12 days after surgery, eight rats were allowed to respond for food presentation under an FR 5 schedule until response rates were stable. Rates of food-maintained responding were similar to baseline rates in those rats (data not shown), suggesting that gonadectomy surgeries did not produce general disruption of operant responding. Accordingly, the remaining rats were not exposed to schedules of food availability after gonadectomy, and cocaine self-administration testing resumed $(1.0 \mathrm{mg} / \mathrm{kg} /$ injection) in all rats 2 weeks after gonadectomy. When criteria for stable self-administration were met (see above), dose-effect tests were conducted.

Estradiol and testosterone replacement. Ovariectomized $(n=8)$ and orchidectomized $(n=8)$ rats were anesthetized with midazolam $(5.0 \mathrm{mg} / \mathrm{kg}$, i.p.) and an isoflurane-oxygen vapor mixture for subcutaneous implantation of steroid treatments. Ovariectomized females were implanted subcutaneously with $0.1 \mathrm{mg}$ estradiol pellets or placebo pellets in the posterior scapular region. The estradiol pellets were reported by the manufacturer (Innovative Research of America, Sarasota, FL) to release a consistent amount of the steroid each day, approximating high physiological levels, for up to 60 days following implantation. Orchidectomized males were implanted subcutaneously with $45 \mathrm{~mm}$ silastic tubing capsules filled with either crystalline testosterone (Sigma Chemical Co., St Louis, MO) or placebo-cholesterol in the posterior scapular region. The testosterone capsules were predicted to result in plasma testosterone levels within the normal physiological range (Damassa et al, 1977). For behavioral studies, on the third day after hormone pellet implantation, cocaine self-administration testing resumed $(1.0 \mathrm{mg} / \mathrm{kg} /$ injection $)$. When criteria for stable self-administration were met (see above), dose-effect tests were conducted. Plasma hormone determinations are described below.

\section{Hormone Status Determinations}

Vaginal cytology. Before cocaine self-administration began, vaginal smears were obtained once per day for at least 5 consecutive days to determine if the rats exhibited regular estrous cycles. Vaginal swabs were performed each morning, at least $2 \mathrm{~h}$ before the operant sessions. Smears were stained with JorVet Dip-Quick stain (Jorgensen Laboratories, Inc., Loveland, $\mathrm{CO}$ ) and examined with a light microscope under $\times 40$ magnification. Phases of the estrous cycle were defined according to the following criteria.
Proestrus days were characterized by the presence of greater than $75 \%$ nucleated epithelial cells. Estrus days were characterized by the presence of greater than $75 \%$ nonnucleated cornified epithelial cells. Diestrus days were characterized by a minimal amount of cells, including leukocytes and occasional cornified epithelia (Grimm and See, 1997).

Plasma hormone concentrations. Studies in separate groups of rats (22 females, 26 males) were conducted to assess plasma estradiol and testosterone concentrations, respectively, after gonadectomy, sham gonadectomy, and hormone replacement conditions. For hormone replacement studies, time points of 7,15 and 28 days after hormone pellet implantation were selected, because all behavioral studies were conducted between 7 and 28 days after hormone pellet implantion, even in cases where implantation of a second catheter was necessary during the course of behavioral testing. Animals were anesthetized with an isoflurane-oxygen vapor mixture and then decapitated. Trunk blood was collected in heparinized tubes, and samples were centrifuged to isolate plasma. Plasma estradiol and testosterone concentrations were measured in duplicate determinations using a direct, double-antibody radioimmunoassay with kits purchased from ICN Biomedical, Inc. (Costa Mesa, CA). For estradiol determinations, the assay sensitivity was $4.3 \mathrm{pg} / \mathrm{ml}$, and intra- and interassay coefficients of variation were 8.6 and $9.8 \%$, respectively. For testosterone determinations, the assay sensitivity was $0.017 \mathrm{ng} / \mathrm{ml}$, and intra- and interassay coefficients of variation were 5.9 and $8.7 \%$, respectively.

\section{Data Analyses}

Food- and cocaine-maintained responding in intact females were compared to the same behaviors in intact males to determine if there were sex differences. The effects of the gonadal steroid hormones estradiol and testosterone on food- and cocaine-maintained responding were examined by comparing behavior before and after gonadectomy or sham gonadectomy, and also by comparing behavior of gonadectomized animals before and after hormone replacement. The effects of gonadectomy and gonadal hormone replacement on circulating levels of gonadal hormones were examined by comparing plasma hormone concentrations in the following five groups of animals: intact animals, gonadectomized animals implanted with placebo pellets, and gonadectomized animals implanted with gonadal hormone pellets for 7, 15, or 28 days. Analyses were conducted using ANOVA with between-subjects factors (sex, gonadal status, hormone replacement status) and/or within-subjects factors with repeated measures (session number, cocaine unit dose, pre- or postgonadectomy or sham-surgery, pre- or posthormone pellet implantation). Significant main effects and significant main interactions were explored by pair-wise comparisons (Fisher's PLSD). The level of significance was 0.05 .

\section{Drugs}

Cocaine hydrochloride was provided by the National Institute on Drug Abuse (NIH) and was dissolved in sterile 
physiological saline. 17ß-estradiol and placebo pellets were purchased from Innovative Research of America (Sarasota, FL). Crystalline testosterone and cholesterol (5-Cholesten$3 ß-$ ol) were purchased from Sigma Chemical Co. (St Louis, MO).

\section{RESULTS}

\section{Acquisition of Operant Responding Maintained by Food}

Table 2 shows data for acquisition of food-maintained responding in gonadally intact female and male rats. Males acquired the behavior slightly more rapidly than females under the FR 1 schedule $\left(\mathrm{F}_{1,34}=6.25, p<0.05\right)$. However, there were no differences between males and females in the number of sessions necessary to meet criteria for food-maintained responding under the FR 5 schedule $\left(\mathrm{F}_{1,34}=1.40, \quad p>0.1\right)$. Although body weights differed between females $(273.8 \pm 6.5 \mathrm{~g})$ and males $(351.0 \pm 4.7 \mathrm{~g})$ during acquisition of food-maintained responding, females and males exhibited comparable increases in body weight over the course of the study $(3.2 \%$ increase per month for females, $3.8 \%$ increase per month for males).

\section{Acquisition of Cocaine Self-Administration}

Figure 1 shows data during acquisition of cocaine selfadministration in males and females (left panels); in gonadally intact and ovariectomized females (center panels); and in gonadally intact and orchidectomized males (right panels). These data are also summarized in Table 2. Gonadally intact male rats reached criteria for stable cocaine self-administration $(1.0 \mathrm{mg} / \mathrm{kg} /$ injection $)$ significantly faster than gonadally intact female rats under these conditions $\left(\mathrm{F}_{1,34}=21.2, p<0.0001\right)$. All of the males reached criteria for stable self-administration behavior within 12 days, whereas an additional 7 days were required for all of

Table 2 Training Sessions to Meet Baseline Criteria (Group Mean and SEM Values)

\begin{tabular}{lcccc}
\hline & $\begin{array}{c}\text { Intact } \\
\text { females }\end{array}$ & Intact males & $\begin{array}{c}\text { OVX } \\
\text { females }\end{array}$ & ORX males \\
\hline $\begin{array}{l}\text { FR I food } \\
\text { maintained } \\
\text { responding }\end{array}$ & $3.6( \pm 0.3)^{\mathrm{a}}$ & $2.7( \pm 0.2)^{\mathrm{a}}$ & & \\
$\begin{array}{l}\text { FR 5 food } \\
\text { maintained } \\
\text { responding }\end{array}$ & $6.1( \pm 0.3)$ & $6.7( \pm 0.4)$ & & \\
$\begin{array}{l}\text { FR 5 cocaine } \\
\text { self- }\end{array}$ & $11.9( \pm 1.0)^{\mathrm{b}}$ & $6.4( \pm 0.7)^{\mathrm{b}}$ & $12.4( \pm 2.1)$ & $8.8( \pm 1.3)$ \\
administration & & & & \\
\hline
\end{tabular}

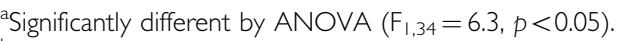

${ }^{b}$ Significantly different by ANOVA $\left(F_{1,34}=21.2, p<0.0001\right)$.

Acquisition of Cocaine Self-Administration
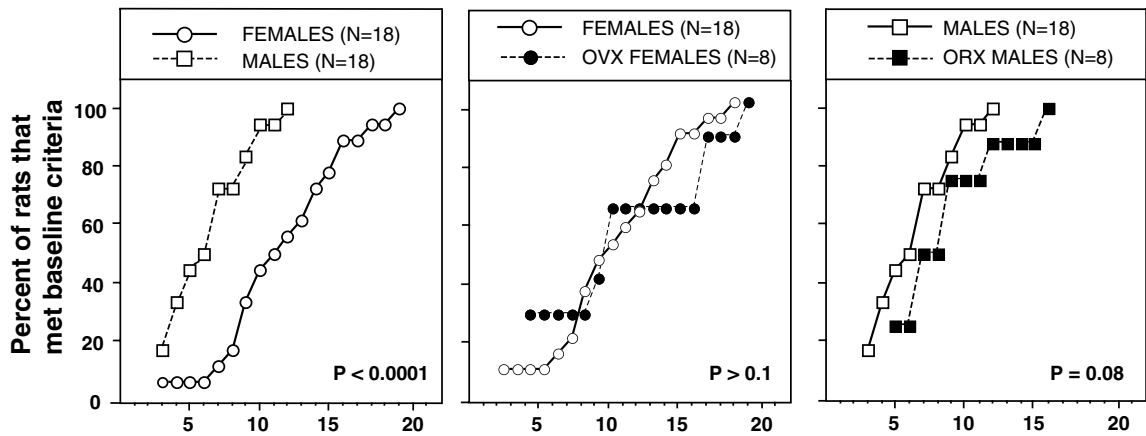

Training session number
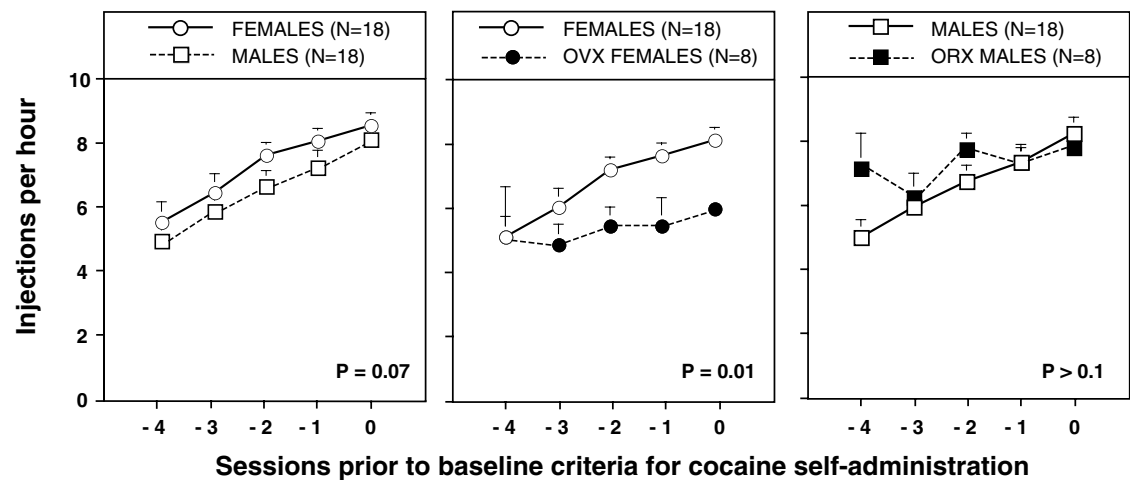

Figure I Acquisition of cocaine self-administration in gonadally intact and gonadectomized female and male rats. Abcissae: overall training session number (top panels) or session number relative to the session in which each rat met criteria for acquisition (bottom panels). Ordinates: percent of rats from each group that met criteria for acquisition (top panels) or mean number of cocaine injections ( $1.0 \mathrm{mg} / \mathrm{kg} / \mathrm{injection}$ ) self-administered per hour (bottom panels). Brackets indicate one SEM. Probability values from ANOVA comparisons (main effect of group) are shown in the bottom right of each panel. 
the females to reach the acquisition criteria (top left panel). During the 5 days immediately preceding acquisition of stable cocaine self-administration for each rat, mean rates of drug intake were comparable for female and male rats (bottom left panel; $\mathrm{F}_{1,34}=3.45, p=0.07$ ).

Ovariectomized females did not differ significantly from intact females in the number of sessions necessary to meet criteria for cocaine self-administration $(1.0 \mathrm{mg} / \mathrm{kg} /$ injection; top center panel; $\left.F_{1,24}=0.06, p>0.1\right)$. However, during the 5 days immediately preceding acquisition of stable cocaine self-administration for each rat, mean rates of drug intake were significantly lower in ovariectomized females compared with intact females (bottom right panel; $\mathrm{F}_{1,24}=7.56$, $p=0.01$.

Orchidectomized males did not differ significantly from intact males in the number of sessions necessary to meet criteria for cocaine self-administration $(1.0 \mathrm{mg} / \mathrm{kg} /$ injection; top right panel; $\mathrm{F}_{1,24}=3.3, p=0.08$ ). Moreover, during the 5 days immediately preceding acquisition of stable cocaine self-administration for each rat, mean rates of drug intake did not differ between orchidectomized and intact males (bottom center panel; $\mathrm{F}_{1,24}=1.52, p>0.1$ ).

\section{Dose-Effect Curves for Cocaine Self-Administration and Concentration-Effect Curves for Liquid Food- Maintained Responding in Gonadally Intact Female and Male Rats}

Figure 2 shows the number of cocaine injections selfadministered as a function of the cocaine unit dose (left panel) and the number of liquid food reinforcers earned as a function of the liquid food concentration (right panel) in gonadally intact female and male rats. Cocaine dose-effect curves were inverted U-shaped functions with the peak at $0.1 \mathrm{mg} / \mathrm{kg} /$ injection in both females and males, and there were no significant differences in dose-effect functions for cocaine self-administration between these two groups of rats $\left(\mathrm{F}_{1,34}=1.58, p>0.1\right)$. Inspection of data from individual rats indicated that dose-effect curves were inverted Ushaped functions with the peak at $0.1 \mathrm{mg} / \mathrm{kg} /$ injection in most of the females $(n=13)$ and males $(n=12)$, and at the next higher dose of cocaine $(0.32 \mathrm{mg} / \mathrm{kg} /$ injection) in all of the other rats. Inspection of vaginal cytology indicated that all of the female rats exhibited estrous cycles during the course of these tests (data not shown). Although estrous cycle phase varied between the two determinations for each dose of cocaine within-subjects, there were no trends for the number of self-administered cocaine injections to vary as a function of estrous cycle phase (data not shown). Responding maintained by various concentrations of liquid food also did not differ between female and male rats across a range of food concentrations under the FR 5 schedule of reinforcement $\left(\mathrm{F}_{1,18}=1.46, p>0.1\right)$.

\section{Effects of Ovariectomy or Orchidectomy on Dose-Effect Curves for Cocaine Self-Administration}

Figure 3 shows the number of cocaine injections selfadministered as a function of the cocaine unit dose in female rats before and after ovariectomy (left panel) and in male rats before and after orchidectomy (right panel). In females, mean dose-effect curves were inverted U-shaped functions with the peak at $0.1 \mathrm{mg} / \mathrm{kg} /$ injection both before and after ovariectomy, and there were no significant differences in dose-effect functions for cocaine self-administration before and after ovariectomy $\left(\mathrm{F}_{1,22}=0.05, p>0.1\right)$. In addition, inspection of data from individual rats indicated that there were no trends for ovariectomy to systematically alter the shape or position of dose-effect functions for cocaine self-administration (individual data not shown).

In males, mean dose-effect curves were inverted U-shaped functions with the peak at 0.1 or $0.32 \mathrm{mg} / \mathrm{kg} /$ injection both before and after orchidectomy, and there were no

\section{Gonadally Intact Female and Male Rats}
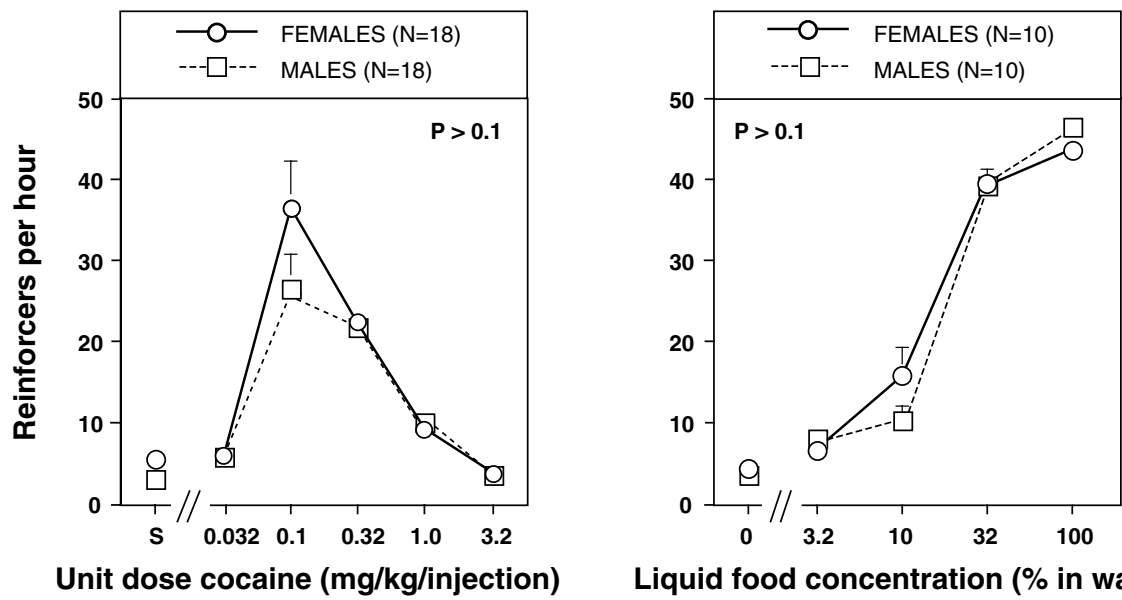

Liquid food concentration (\% in water)

Figure 2 Dose-effect curves for cocaine self-administration and concentration-effect functions for liquid food-maintained responding in gonadally intact female and male rats. Abcissa: unit dose of cocaine in $\mathrm{mg} / \mathrm{kg} /$ injection (doses were adjusted according to the body weight of each individual rat) or liquid food concentration (Ensure protein drink diluted in water). Points above S show data for i.v. saline injections (left panel) and points above zero show data for water presentation (right panel). Ordinate: mean number of self-administered injections or liquid food reinforcers earned per hour. Brackets indicate one SEM. The probability value from an ANOVA comparison (main effect of group) is shown in the top of each panel. 
Pre- and Post-Ovariectomy and Orchidectomy

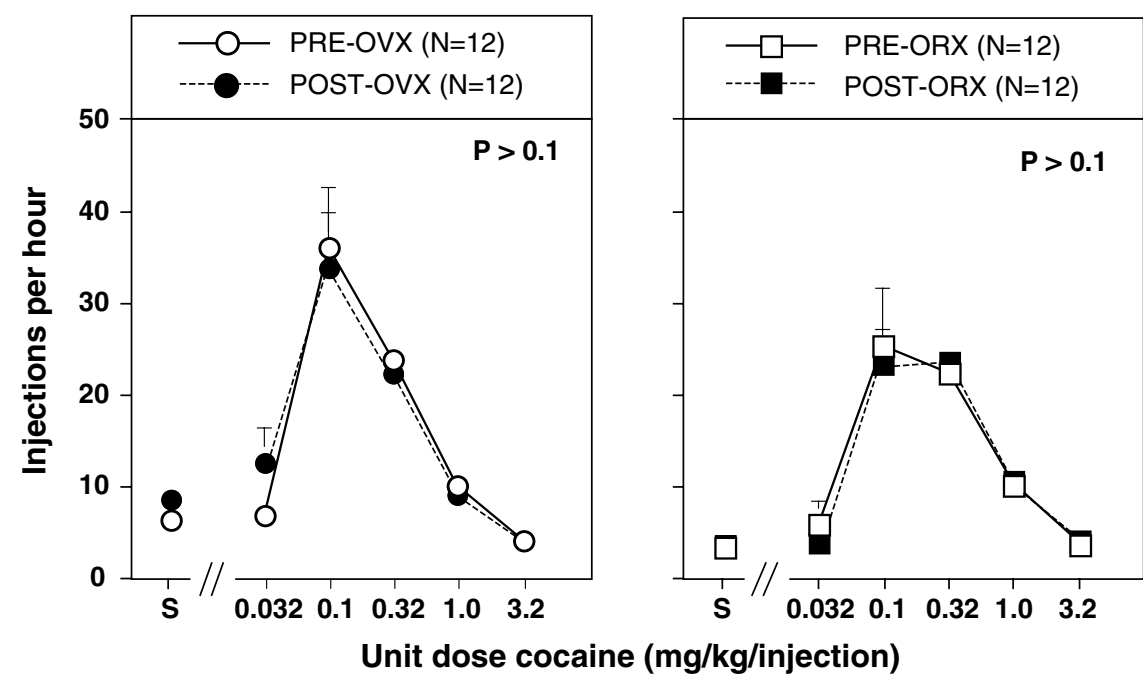

Figure 3 Dose-effect curves for cocaine self-administration determined before and after ovariectomy or orchidectomy surgery. Abcissa: unit dose of cocaine in $\mathrm{mg} / \mathrm{kg} /$ injection. Points above $\mathrm{S}$ show data for i.v. saline injections. Ordinate: mean number of self-administered injections per hour. Brackets indicate one SEM. The probability value from ANOVA comparisons (main effect of ovariectomy or orchidectomy) is shown in the top right of each panel.

significant differences in dose-effect functions for cocaine self-administration before and after orchidectomy $\left(\mathrm{F}_{1,22}=0.07, p>0.1\right)$. In addition, inspection of data from individual rats indicated that there were no trends for orchidectomy or sham surgery to systematically alter the shape or position of dose-effect functions for cocaine selfadministration (individual data not shown).

Control studies were also conducted with female and male rats before and after sham ovariectomy or orchidectomy (data not shown). There were no significant differences for either females or males in dose-effect functions for cocaine self-administration before and after sham-gonadectomy surgery $\left(n=6 ;\right.$ sham-ovariectomy, $\mathrm{F}_{1,10}=0.17, \quad p>0.1$; sham-orchidectomy, $\mathrm{F}_{1,10}=0.86, p>0.1$ ). For females, mean dose-effect curves were inverted U-shaped functions with the peak at $0.1 \mathrm{mg} / \mathrm{kg} /$ injection both before and after sham surgery, and for males mean dose-effect curves were inverted U-shaped functions with the peak at 0.1 or $0.32 \mathrm{mg} / \mathrm{kg} /$ injection both before and after sham surgery. Inspection of data from individual male rats indicated that the dose of cocaine at the peak of the dose-effect function increased by one-half log unit in three rats and decreased by one-half log unit in two other rats after sham surgery. Thus, there were no trends for sham-orchidectomy surgery to systematically alter the shape or position of dose-effect functions for cocaine self-administration.

\section{Effect of Estradiol or Testosterone Replacement on Dose-Effect Curves for Cocaine Self-Administration}

Figure 4 shows the number of cocaine injections selfadministered as a function of the cocaine unit dose in ovariectomized female rats before and after estradiol replacement (left panel) and in orchidectomized male rats before and after testosterone replacement (right panel). Mean dose-effect curves were inverted U-shaped functions with the peak at $0.1 \mathrm{mg} / \mathrm{kg} /$ injection both before and after gonadal hormone replacement, and there were no significant differences in dose-effect functions for cocaine self-administration before and after gonadal hormone replacement in gonadectomized female and male rats (females, $\mathrm{F}_{1,14}=0.55, p>0.1$; males, $\mathrm{F}_{1,14}=0.10, p>0.1$ ). In addition, inspection of data from individual rats indicated that there were no trends for gonadal hormone replacement to systematically alter the shape or position of dose-effect functions for cocaine self-administration in gonadectomized female and male rats (individual data not shown).

\section{Plasma Concentrations of Estradiol And Testosterone}

Figure 5 shows plasma estradiol (left panel) and testosterone (right panel) concentrations under various conditions in five groups of female rats and five groups of male rats. The conditions for female rats were as follows: intact rats $(n=6)$, ovariectomized rats implanted with a cholesterol pellet for 7 days $(n=5)$, and ovariectomized rats implanted with a $0.1 \mathrm{mg}$ estradiol pellet for 7 days $(n=2), 15$ days $(n=5)$, or 28 days $(n=4)$. Concentrations of estradiol varied considerably among individual intact females (from 5.9 to $73.9 \mathrm{pg} / \mathrm{ml}$ ), and the mean value was $27.5 \mathrm{pg} / \mathrm{ml}$ of estradiol. Estradiol concentrations were significantly different among the five groups of female rats $\left(\mathrm{F}_{4,17}=10.6\right.$, $p<0.001)$. The mean estradiol concentration in ovariectomized rats implanted with cholesterol pellets was $4.9 \mathrm{pg} / \mathrm{ml}$, and was significantly lower than estradiol levels in intact females $(p<0.05)$. In ovariectomized rats implanted with estradiol pellets $(0.1 \mathrm{mg})$, mean estradiol concentrations were $66.2,53.5$ and $43.6 \mathrm{pg} / \mathrm{ml}$ after 7,15 , and 28 days, respectively. Estradiol concentrations in ovariectomized females implanted with estradiol pellets were higher than estradiol levels in ovariectomized females implanted with cholesterol pellets and in intact females at 7 and 15 days after pellet implantation $(p<0.01)$ but not at 28 days after pellet implantation $(p>0.1)$. 


\section{Gonadectomized Rats Pre- and Post- Hormone Replacement}

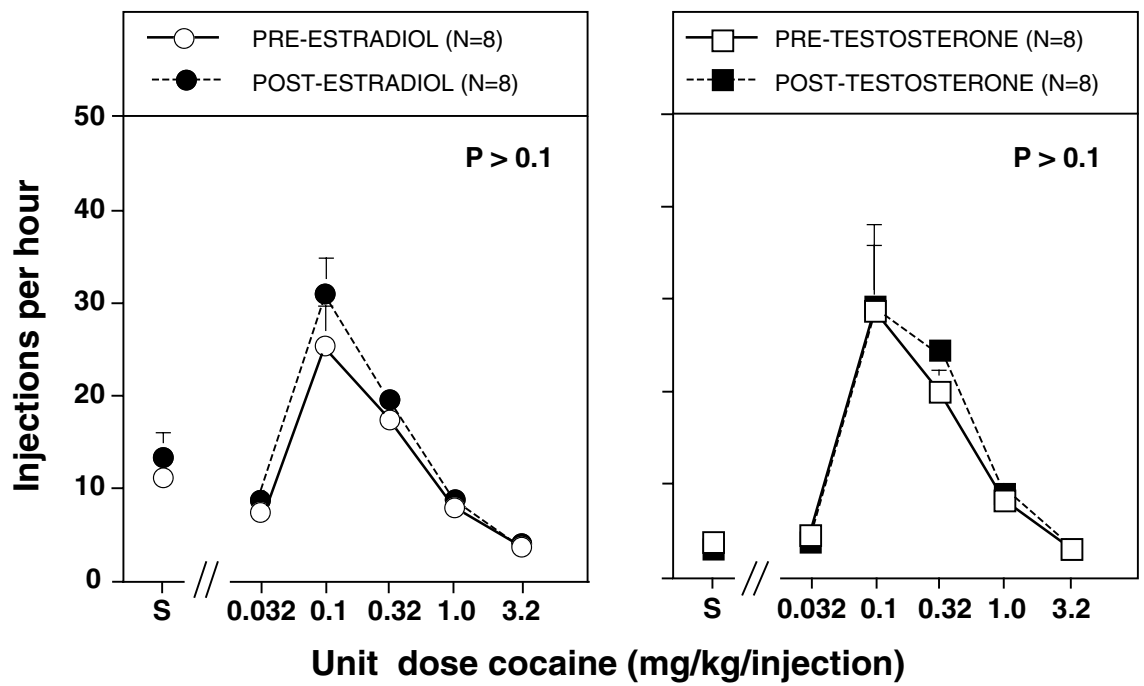

Figure 4 Dose-effect curves for cocaine self-administration determined before and after gonadal hormone replacement in gonadectomized female and male rats. Abcissa: unit dose of cocaine in $\mathrm{mg} / \mathrm{kg} /$ injection. Points above $\mathrm{S}$ show data for i.v. saline injections. Ordinate: mean number of self-administered injections per hour. Brackets indicate one SEM. The probability value from ANOVA comparisons (main effect of orchidectomy or sham surgery) is shown in the top right of each panel.

Hormone Concentrations in Intact, Gonadectomized and Hormone-Pelleted Rats
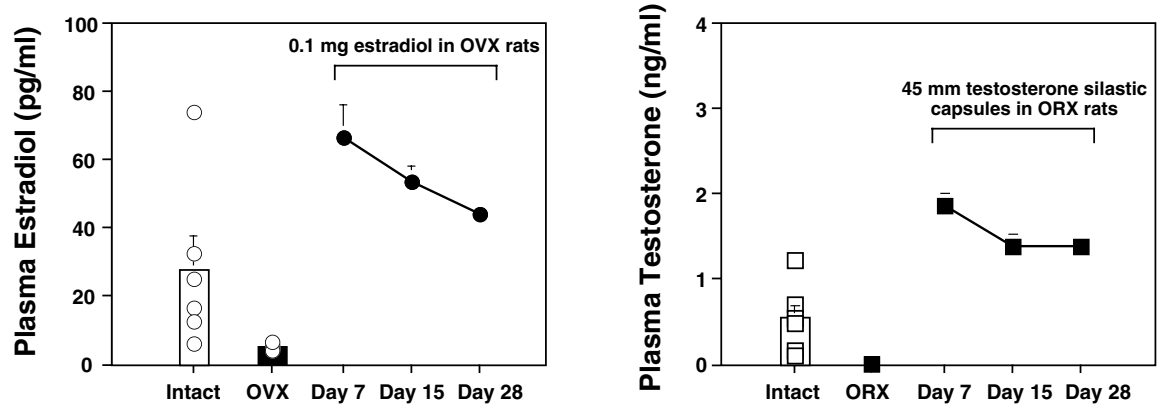

Figure 5 Plasma hormone concentrations in intact, gonadectomized and hormone-treated female and male rats. Abcissa: experimental group including intact rats, gonadectomized rats with cholesterol treatment for seven days and gonadectomized rats with hormone replacement for 7,15 or 28 days. Ordinate: plasma estradiol concentration (left panel, pg/ml) or testosterone concentration (right panel, $\mathrm{ng} / \mathrm{ml}$ ). Brackets indicate one SEM. Symbols over 'Intact', 'OVX' and 'ORX' depict values from individual rats, and all other symbols (histograms, filled circles and filled squares) depict group mean values. Brackets indicate one SEM.

The conditions for male rats were as follows: intact rats $(n=6)$, orchidectomized rats implanted with a cholesterolfilled $45 \mathrm{~mm}$ silastic capsule for 7 days $(n=4)$, and orchidectomized rats implanted with a testosterone-filled $45 \mathrm{~mm}$ silastic capsule for 7 days $(n=6), 15$ days $(n=5)$, or 28 days $(n=5)$. Concentrations of testosterone varied considerably among individual intact males (from 0.089 to $1.219 \mathrm{ng} / \mathrm{ml}$ ), and the mean value was $0.526 \mathrm{ng} / \mathrm{ml}$ of testosterone. Testosterone concentrations were significantly different among the five groups of male rats $\left(\mathrm{F}_{4,21}=28.1\right.$, $p<0.0001)$. Testosterone concentrations in orchidectomized rats implanted with cholesterol-filled capsules were undetectable up to the sensitivity of the assay $(0.017 \mathrm{ng} / \mathrm{ml})$, and this was significantly different from testosterone levels in intact males $(p<0.05)$. In orchidectomized rats implanted with testosterone-filled capsules, mean testosterone concentrations were 1.852, 1.383, and $1.380 \mathrm{ng} / \mathrm{ml}$ after 7,15 , and 28 days, respectively. Testosterone concentrations in orchidectomized males implanted with testosterone-filled capsules were higher than testosterone concentrations in orchidectomized males implanted with cholesterol-filled capsules and in intact males at all time points $(p<0.001)$.

\section{DISCUSSION}

These studies were designed to examine the influence of sex and gonadal hormone levels on complete dose-effect functions for cocaine self-administration under an FR 5 
schedule of reinforcement. Our four major findings were as follows:

(1) When acquisition of cocaine self-administration (1.0 mg/kg/injection) under an FR schedule was evaluated following operant training with food reinforcement, gonadally intact females reached the acquisition criteria more slowly than males. However, during the final stages of acquisition, levels of cocaine self-administration were comparable between intact females and males.

(2) When complete dose-effect curves for cocaine selfadministration were examined $(0.032-3.2 \mathrm{mg} / \mathrm{kg} /$ injection) under an FR 5 schedule of reinforcement, there were no significant differences between gonadally intact females and males in the shape or position of the cocaine dose-effect curves.

(3) Ovariectomy in females and orchidectomy in males did not significantly alter the shape or position of doseeffect curves for cocaine self-administration under an FR 5 schedule of reinforcement.

(4) Chronic administration of estradiol to ovariectomized females and testosterone to orchidectomized males also did not alter the shape or position of dose-effect curves for cocaine self-administration under the FR 5 schedule of reinforcement.

Taken together, the findings of the present study indicate that the potency and effectiveness of i.v. cocaine as a reinforcing stimulus do not differ between female and male rats under these conditions. These findings also indicate that gonadectomy and subsequent replacement of estradiol and testosterone levels do influence cocaine's reinforcing effects in rats under these conditions. The relationship of these data to previous studies of sex and gonadal-steroid hormone influences on cocaine's behavioral effects is discussed below.

\section{Comparison with Previous Studies in Rats}

A number of previous studies examined effects of sex or gonadal hormone status on cocaine self-administration in rats (Roberts et al, 1989; Grimm and See, 1997; Lynch and Carroll, 1999; Lynch et al, 2001; Carroll et al, 2002; Hu et al, 2003). In all of those studies, only a single dose of cocaine or a very narrow range of cocaine doses was evaluated. The present study extends findings from previous studies in that complete dose-effect curves for cocaine self-administration were determined. One advantage of complete dose-effect curve determinations is that sex or gonadal hormone status may affect self-administration of some cocaine doses but not others (see below). A second advantage of this approach is that the position and shape of the curve can be used to assess effects of sex or gonadal hormone status on the potency and efficacy of cocaine (Mello and Negus, 1996). A third advantage is that the ascending and descending limbs of the dose-effect function for cocaine self-administration may reflect different behavioral effects of cocaine (Katz, 1989), and differences between experimental groups may be detected on only one limb of the function (Caine et al, 2002). In the present study, sex and gonadal hormone status did not influence cocaine self-administration across a broad range of doses, and did not alter the overall shape and position of complete dose-effect functions for cocaine self- administration, including both ascending and descending limbs of the function.

\section{Sex Differences in Cocaine Self-Administration: Importance of Behavioral History, Schedule of Reinforcement and Unit Dose}

In contrast to the present findings, results from several previous studies suggested that intact females may be more sensitive than intact males to the reinforcing effects of cocaine under conditions that differed from those in the present study (Roberts et al, 1989; Lynch and Carroll, 1999; Carroll et al, 2002). Critical differences between the conditions of those studies and the present study include the training of food-maintained responding before evaluating cocaine self-administration, the schedule of reinforcement (FR) and the unit dose of cocaine $(1.0 \mathrm{mg} / \mathrm{kg} /$ injection). For example, in several previous studies, intact female rats acquired cocaine self-administration more rapidly than intact male rats (Lynch and Carroll, 1999; Carroll et al, 2002), and in contrast, in the present study intact females acquired cocaine self-administration more slowly than intact males. In those previous studies, rats did not have a behavioral history of operant training prior to evaluation of acquisition of cocaine self-administration. We trained rats with food-maintained responding prior to evaluation of cocaine self-administration to eliminate potential performance differences that could affect acquisition of operant responding maintained by cocaine injections. We also found that after the training criteria were met, females and males did not differ when responding was maintained by presentation of a range of liquid food concentrations or water. These results suggest that female and male rats in this study did not differ in their operant behavior prior to the introduction of cocaine as a reinforcer.

In addition to no prior operant training, other important variables in previous studies where females were more sensitive than males to the reinforcing effects of cocaine included the use of a specialized autoshaping procedure and a relatively low training dose of cocaine $(0.2 \mathrm{mg} / \mathrm{kg} /$ injection; Lynch and Carroll, 1999; Carroll et al, 2002), or the use of a PR schedule (Roberts et al, 1989). In other studies, no sex differences were observed for acquisition or maintenance of self-administration of slightly higher cocaine doses $(0.32-0.5 \mathrm{mg} / \mathrm{kg} /$ injection) under an FR 1 schedule (Roberts et al, 1989; Haney et al, 1995). However, sex differences were observed when a relatively high cocaine dose ( $0.6 \mathrm{mg} /$ injection) was available under a PR schedule (Roberts et al, 1989). In the present study, females acquired self-administration of a high cocaine dose $(1.0 \mathrm{mg} / \mathrm{kg} /$ injection) more slowly than males under an FR schedule, and no sex differences were observed in the maintenance of self-administration of a broad range of cocaine doses under an FR schedule. Collectively, the present results and those from previous studies suggest that sex differences in cocaine self-administration are not consistently observed across a wide range of conditions, and are probably dependent upon the behavioral history of the subjects, the schedule of reinforcement, the unit dose of cocaine and other experimental variables. 
Effects of Gonadectomy and Gonadal Hormone Replacement on Cocaine Self-Administration

In the present study, gonadectomy did not facilitate or impair the acquisition of cocaine self-administration $(1.0 \mathrm{mg} / \mathrm{kg} /$ injection $)$ in females and males, although ovariectomized females self-administered slightly less cocaine than intact females during the final stages of acquisition. After acquisition of cocaine self-administration, gonadal hormone replacement in gonadectomized rats did not alter self-administration of any cocaine dose under an FR 5 schedule. Consistent with the results of the present study, in one earlier study all ovariectomized rats learned to self-administer cocaine $(0.219 \mathrm{mg} /$ injection, not adjusted for body weights) under an FR 1 schedule of reinforcement, and once rats acquired self-administration, chronic estradiol treatment did not significantly change the average daily cocaine intake (Grimm and See, 1997). There were also no significant differences in cocaine self-administration under a PR schedule between ovariectomized females treated chronically with estradiol or vehicle (Grimm and See, 1997). However, in two previous studies, estradiol administration to ovariectomized rats facilitated acquisition of self-administration of low cocaine doses $(0.2-0.3 \mathrm{mg} / \mathrm{kg} /$ injection) in an autoshaping procedure or under an FR 1 schedule (Lynch et al, 2001; Hu et al, 2003). In addition, in both the present study and a previous study ( $\mathrm{Hu}$ et al, 2003), orchidectomy did not alter cocaine self-administration in male rats. Collectively, these findings suggest that an influence of ovariectomy and estradiol administration on the reinforcing effects of cocaine are more likely to be observed during acquisition with low cocaine doses, and an influence of gonadectomy and gonadal hormone administration on the reinforcing effects of cocaine are less likely to be observed under other conditions.

\section{Comparison with Findings from Studies of Conditioned} Place Preference and Motor Activity

Generally, the reinforcing effects of the psychomotor stimulant drugs cocaine, amphetamine, and methamphetamine measured with the conditioned place preference procedure did not significantly differ between female and male rats (Schechter, 1992; Bardo et al, 1995; Stöhr et al, 1998; Schindler et al, 2002). However, trends toward greater effects of low doses in females relative to males were observed in several of those studies. Moreover, in one recent study, conditioned place preferences were observed with lower $(5.0-10.0 \mathrm{mg} / \mathrm{kg})$ but not higher $(20.0 \mathrm{mg} / \mathrm{kg})$ cocaine doses in female rats, and the reverse was found with male rats (Russo et al, 2003a), and it was suggested that this sex difference reflected ovarian hormone levels (Russo et al, 2003b). Conditioned place preferences observed in female rats with lower but not higher cocaine doses may be related to the slower acquisition of cocaine self-administration in female relative to male rats in the present study, in that a relatively high training dose was used $(1.0 \mathrm{mg} / \mathrm{kg} /$ injection). Taken together, the present and previous findings suggest that under some conditions, low cocaine doses may be more effective in females and high cocaine doses may be more effective in males during acquisition of either self-administration or conditioned place preferences in rats. Never- theless, there were no effects of sex or gonadal hormone levels on complete dose-effect curves during maintenance of cocaine self-administration in female and male rats in the present study.

Whereas sex, gonadectomy and subsequent hormone administration had no effect on dose-effect curves for cocaine self-administration in the present study, these variables significantly affected cocaine-induced locomotor activity in a number of previous studies (Sell et al, 2000, 2002; Sircar and Kim, 1999; Walker et al, 2001; Haney et al, 1994; Kuhn et al, 2001; Chin et al, 2002; Schindler and Carmona, 2002; Hu and Becker, 2003).

\section{Effect of Gonadal Hormone Administration on Gonadal Hormone Blood Levels}

One limitation of most studies of the effects of estrogen in ovariectomized rats is that direct measures of $17 \beta$-estradiol levels in plasma are not reported. Rather, dose levels are estimated, and physiological relevance is verified with measures of vaginal cytology. In the present study, both vaginal cytology and plasma estradiol and testosterone concentrations after gonadectomy and hormone replacement were analyzed. As expected, gonadectomy decreased gonadal hormone levels, and estradiol and testosterone implanted pellets produced hormone levels that were sustained over 28 days. Estradiol and testosterone levels in gonadectomized rats were in the physiological range usually reported in the literature (Bridges, 1984), and at the high end of the physiological range observed in intact rats in the present study.

Limitations of the present study are that only a single chronic dose-regimen for each steroid hormone, and only one hormone, estradiol or testosterone, was administered to gonadectomized rats. We chose not to study hormone combinations because the interactions between the steroid hormones are very complex (see for a review O'Malley and Strott, 1999). For example, although combinations of estradiol and progesterone may enhance cocaine-induced locomotor activity under some conditions (Sell et al, 2000; Sircar and Kim, 1999), there is also considerable evidence that progesterone may antagonize the endocrine effects of estradiol (Clark and Mani, 1994; Dierschke et al, 1973; VanVugt et al, 1992; Wildt et al, 1981). Accordingly, examination of the effects of a single hormone, rather than hormone combinations, seemed appropriate for this initial series of studies.

Finally, acute and chronic administration of gonadal steroid hormones stimulate dopamine release under many conditions (Becker and Rudick, 1999; Castner et al, 1993; McDermott et al, 1994; Pasqualini et al, 1995, 1996; Thompson and Moss, 1994; Toney et al, 1992), and gonadal steroid hormones are also directly stimulated by cocaine in rhesus monkeys (Mello et al, 1993, 2000). In the present study, cocaine self-administration dose-effect curves were not affected by gonadectomy or by chronic steroid hormone administration in gonadectomized rats. Acute steroid treatment produces rapid-onset, nongenomic effects whereas chronic steroid treatment produces slow-onset genomic effects (Thompson and Moss, 1994; see for a review Falkenstein et al, 2000). Thus, comparisons of effects of acute $v s$ chronic administration of gonadal hormones in 
cocaine self-administration studies, and understanding the behavioral implications of stimulation of rapid endocrine changes by cocaine administration, remain areas for further investigation (Mendelson et al, 2002, 2003; Mello and Mendelson, 2002).

\section{Summary and Conclusions}

Sex and gonadectomy did not alter the potency or effectiveness of cocaine as a reinforcer when cocaine doseeffect curves were evaluated under an FR 5 schedule. Moreover, chronic administration of estradiol and testosterone to gonadectomized female and male rats did not alter cocaine self-administration dose-effect curves. Critical features of this study include operant training with food reinforcement prior to acquisition of self-administration of a relatively high cocaine dose $(1.0 \mathrm{mg} / \mathrm{kg} /$ injection $)$ under an FR schedule. These results are in agreement with results from some previous studies that used similar conditions, and contrast with results from some previous studies in which experimentally naïve rats self-administered low unit doses of cocaine during acquisition of self-administration, or operant experienced rats self-administered high unit doses of cocaine under a PR schedule of reinforcement. These data also contrast with findings from studies of locomotor activity where sex and gonadal hormone levels consistently influenced the effects of cocaine. Taken together with previous findings, these results suggest that operant training history, the unit dose of cocaine, and the schedule of reinforcement all are critical determinants of the influence of sex and gonadal hormones on cocaine selfadministration. In addition, factors that influence other behavioral effects of cocaine, such as motor activation, do not necessarily predict effects on cocaine self-administration. In conclusion, under the conditions used in the present study, sex, estrogen, and testosterone levels did not significantly influence the reinforcing effects of cocaine in rats.

\section{ACKNOWLEDGEMENTS}

We thank Jen Dohrmann and Maureen Kelly for outstanding technical assistance, and the National Institute on Drug Abuse for supporting these studies (R29-DA12142, R01-DA14670, K05-DA00101, P01-DA14528).

\section{REFERENCES}

Anderson KG, van Haaren F (1999). Cocaine discrimination and time-course effects in male and female Wistar rats. Eur $J$ Pharmacol 382: 69-74.

Anderson KG, van Haaren F (2000). Effects of SCH 23390 and raclopride in cocaine discrimination in male and female Wistar rats. Pharmacol Biochem Behav 65: 671-675.

Bardo MT, Rowlett JK, Harris MJ (1995). Conditioned place preference using opiate and stimulant drugs: a meta-analysis. Neurosci Biobehav Rev 19: 39-51.

Becker JB, Cha JH (1989). Estrous cycle-dependent variation in amphetamine-induced behaviors and striatal dopamine release assessed with microdialysis. Behav Brain Res 35: 117-125.

Becker JB, Rudick CN (1999). Rapid effects of estrogen or progesterone on the amphetamine-induced increase in striatal dopamine are enhanced by estrogen priming: a microdialysis study. Pharmacol Biochem Behav 64: 53-57.

Becker JH, Robinson TE, Lorenz KA (1982). Sex differences and estrous cycle variations in amphetamine-elicited rotational behavior. Eur J Pharmacol 90: 66-72.

Bridges RS (1984). A quantitative analysis of the roles of dosage, sequence, and duration of estradiol and progesterone exposure in the regulation of maternal behavior in the rat. Endocrinology 114: 930-940.

Caine SB, Lintz R, Koob GF (1993). Intravenous drug selfadministration techniques in animals. In: Sahgal A (ed). Behavioral Neuroscience: A Practical Approach. Oxford University Press: Oxford. pp 117-143.

Caine SB, Negus SS, Mello NK, Patel S, Bristow L, Kulagowski J et al (2002). Role of dopamine D2-like receptors in cocaine selfadministration: studies with D2 receptor mutant mice and novel D2 receptor antagonists. J Neurosci 22: 2977-2988.

Camp DM, Becker JB, Robinson TE (1986). Sex differences in the effects of gonadectomy on amphetamine-induced rotational behavior in rats. Behav Neural Biol 46: 491-495.

Carroll ME, Morgan AD, Lynch WJ, Campbell UC, Dess NK (2002). Intravenous cocaine and heroin self-administration in rats selectively bred for differential saccharin intake phenotype and sex differences. Psychopharmacology 161: 304-313.

Castner SA, Xiao L, Becker JB (1993). Sex differences in striatal dopamine: in vivo microdialysis and behavioral studies. Brain Res 610: 127-134.

Chin J, Sternin O, Wu HB, Burrell S, Lu D, Jenab S et al (2002). Endogenous gonadal hormones modulate behavioral and neurochemical responses to acute and chronic cocaine administration. Brain Res 945: 123-130.

Clark UH, Mani SK (1994). Actions of ovarian steroid hormones. In: Knobil E, Neill JD (ed). The Physiology of Reproduction, 2nd edn Raven Press, Ltd.: New York. pp 1011-1059.

Cosgrove KP, Hunter RG, Carroll ME (2002). Wheel-running attenuates intravenous cocaine self-administration in rats Sex differences. Pharmacol Biochem Behav 73: 663-671.

Craft RM, Stratmann JA (1996). Discriminative stimulus effects of cocaine in female versus male rats. Drug Alcohol Depend 42: 27-37.

Damassa DA, Smith ER, Tennent B, Davidson JM (1977). The relationship between circulating testosterone levels and male sexual behavior in rats. Hormones Behav 8: 275-286.

Dierschke DJ, Yamaji T, Karsch FJ, Weick RF, Weiss G, Knobil E (1973). Blockade by progesterone of estrogen-induced LH and FSH release in the rhesus monkey. Endocrinology 92: 1496-1501.

Evans SM, Haney M, Foltin RW (2002). The effects of smoked cocaine during the follicular and luteal phases of the menstrual cycle in women. Psychopharmacology 159: 397-406.

Falkenstein E, Tillmann H-C, Christ M, Feuring M, Wehling M (2000). Multiple actions of steroid hormones - a focus on rapid, nongenomic effects. Pharmcol Rev 52: 513-555.

Grimm JW, See RE (1997). Cocaine self-administration in ovariectomized rats is predicted by response to novelty, attenuated by 17- $\beta$ estradiol, and associated with abnormal vaginal cytology. Physiol Behav 61: 755-761.

Haney M, Castanon N, Cador M, Le Moal M, Mormede P (1994). Cocaine sensitivity in Roman High and Low Avoidance rats is modulated by sex and gonadal hormone status. Brain Res 645: 48-52.

Haney M, Maccari S, Le Moal M, Simon H, Piazza PV (1995). Social stress increases the acquisition of cocaine self-administration in male and female rats. Brain Res 698: 46-52.

Hu M, Becker JB (2003). Effects of sex and estrogen on behavioral sensitization to cocaine in rats. J Neurosci 23: 693-699.

Hu M, Crombag HS, Robinson TE, Becker JB (2003). Biological basis of sex differences in the propensity to self-administer cocaine. Neuropsychopharmacology, online publication 1 August 
2003 at http://www.acnp.org/citations/NPP08010303155/default.pdf.

Hull EM, Du J, Lorrain DS, Matuszewich L (1997). Testosterone, preoptic dopamine, and copulation in male rats. Brain Res Bull 44: 327-333.

Katz JL (1989). Drugs as reinforcers: pharmacological and behavioural factors. In: Liebman JM, Cooper SJ (ed). The Neuropharmacological Basis of Reward. Clarendon Press: Oxford. pp 164-213.

Kosten TR, Kosten TA, McDougle CJ, Hameedi FA, McCance EF, Rosen MI et al (1996). Gender differences in response to intranasal cocaine administration to humans. Biol Psychiatry 39: 147-148.

Kuhn CM, Walker QD, Kaplan KA, Li ST (2001). Sex, steroids, and stimulant sensitivity. In: Quinones-Jenab V (ed). The Biological Basis of Cocaine Addiction. The New York Academy of Sciences: New York. pp 188-201.

Long SF, Dennis LA, Russell RK, Benson KA, Wilson MC (1994). Testosterone implantation reduces the motor effects of cocaine. Behav Pharmacol 5: 103-106.

Lukas SE, Sholar M, Lundahl LH, Lamas X, Kouri E, Wines JD et al (1996). Sex differences in plasma cocaine levels and subjective effects after acute cocaine administration in human volunteers. Psychopharmacology 125: 346-354.

Lynch WJ, Carroll ME (1999). Sex differences in the acquisition of intravenously self-administered cocaine and heroin in rats. Psychopharmacology 144: 77-82.

Lynch WJ, Carroll ME (2000). Reinstatement of cocaine selfadministration in rats: sex differences. Psychopharmacology 148: 196-200.

Lynch WJ, Roth ME, Carroll ME (2002). Biological basis of sex differences in drug abuse: preclinical and clinical studies. Psychopharmacology 164: 121-137.

Lynch WJ, Roth ME, Mickelberg JL, Carroll ME (2001). Role of estrogen in the acquisition of intravenously self-administered cocaine in female rats. Pharmacol Biochem Behav 68: 641-646.

Martinez-Sanchez A, Aragon CM, Salvador A (2002). Cocaine induced locomotor activity is enhanced by exogenous testosterone. Physiol Behav 76: 605-609.

McDermott JL, Liu B, Dluzen DE (1994). Sex differences and effects of estrogen on dopamine and DOPAC release from the striatum of male and female CD-1 mice. Exp Neurol 125: 306-311.

Mello NK, Mendelson JH (2002). Cocaine, hormones and behavior: clinical and preclinical studies. In: Pfaff DW, Arnold AP, Etgen AM, Fahrbach SE, Rubin RT (eds). Hormones, Brain and Behavior. Academic Press, New York. pp 665-745.

Mello NK, Mendelson JH, Kelly M, Bowen CA (2000). The effects of cocaine on basal and human chorionic gonadotropin-stimulated ovarian steroid hormones in female rhesus monkeys. J Pharmacol Exp Ther 294: 1137-1145.

Mello NK, Negus SS (1996). Preclinical evaluation of pharmacotherapies for treatment of cocaine and opioid abuse using drug self-administration procedures. Neuropsychopharmacology 14: 375-424.

Mello NK, Sarnyai Z, Mendelson JH, Drieze JM, Kelly M (1993). Acute effects of cocaine on anterior pituitary hormones in male and female rhesus monkeys. J Pharmacol Exp Ther 266: 804-811.

Mendelson JH, Mello NK, Sholar MB, Siegel AJ, Kaufman MJ, Levin JM et al (1999). Cocaine pharmacokinetics in men and in women during the follicular and luteal phase of the menstrual cycle. Neuropsychopharmacology 21: 294-303.

Mendelson JH, Mello NK, Sholar MB, Siegel AJ, Mutschler N, Halpern J (2002). Temporal concordance of cocaine effects on mood states and neuroendocrine hormones. Psychoneuroendocrinology 27: 71-82.

Mendelson JH, Sholar MB, Muschler NH, Jaszyna-Gasior M, Goletiani NV, Siegel AJ et al (2003). Effects of intravenous cocaine and cigarette smoking on luteinizing hormone, testo- sterone, and prolactin in men. J Pharmacol Exp Ther 307: 339-348.

O'Malley BW, Strott CA (1999). Steroid hormones: metabolism and mechanism of action. In: Yen SSC, Jaffe RB, Barbieri RL (eds). Reproductive Endocrinology: Physiology, Pathophysiology, and Clinical Management. W.B. Saunders Company: Philadelphia, PA. pp 110-133.

Pasqualini C, Olivier V, Guibert B, Frain O, Leviel V (1995). Acute stimulatory effect of estradiol on striatal dopamine synthesis. J Neurochem 65: 1651-1657.

Pasqualini C, Olivier V, Gluibert B, Frain O, Leviel V (1996). Rapid stimulation of striatal dopamine synthesis by estradiol. Cell Mol Neurobiol 16: 411-415.

Peris J, Decambre N, Coleman-Hardee ML, Simpkins JW (1991). Estradiol enhances behavioral sensitization to cocaine and amphetamine-stimulated striatal $[3 \mathrm{H}]$ dopamine release. Brain Res 566: 255-264.

Quinones-Jenab V, Ho A, Schlussman SD, Franck J, Kreek MJ (1999). Estrous cycle differences in cocaine-induced stereotypic and locomotor behaviors in Fischer rats. Behav Brain Res 101: $15-20$.

Roberts DSC, Bennett SA, Vickers GJ (1989). The estrous cycle affects cocaine self-administration on a progressive ratio schedule in rats. Psychopharmacology (Berlin) 98: 408-411.

Russo SJ, Festa ED, Fabian SJ, Gazi FM, Kraish M, Jenab S et al (2003b). Gonadal hormones differentially modulate cocaineinduced conditioned place preference in male and female rats. Neuroscience 120: 523-533.

Russo SJ, Jenab S, Fabian SJ, Festa ED, Kemen LM, Quinones-Jenab $\mathrm{V}$ (2003a). Sex differences in the conditioned rewarding effects of cocaine. Brain Res 970: 214-220.

Savageau MM, Beatty WW (1981). Gonadectomy and sex differences in the behavioral responses to amphetamine. Pharmacol Biochem Behav 14: 17-21.

Schechter MD (1992). Rats bred for differences in preference to cocaine: other behavioral measures. Pharmacol Biochem Behav 43: 1015-1021.

Schindler CW, Bross JG, Thorndike EB (2002). Gender differences in the behavioral effects of methamphetamine. Eur J Pharmacol 442: 231-235.

Schindler CW, Carmona GN (2002). Effects of dopamine agonists and antagonists on locomotor activity in male and female rats. Pharmacol Biochem Behav 72: 857-863.

Schneider BF, Norton S (1979). Circadian and sex differences in hyperactivity produced by amphetamine in rats. Physiol Behav 22: 47-51.

Sell SL, Scalzitti JM, Thomas ML, Cunningham KA (2000). Influence of ovarian hormones and estrous cycle on the behavioral response to cocaine in female rats. J Pharmacol Exp Ther 293: 879-886.

Sell SL, Thomas ML, Cunningham KA (2002). Influence of estrous cycle and estradiol on behavioral sensitization to cocaine in female rats. Drug Alcohol Depend 67: 281-290.

Sircar R, Kim D (1999). Female gonadal hormones differentially modulate cocaine-induced behavioral sensitization in Fischer, Lewis, and Sprague-Dawley Rats. J Pharmacol Exp Ther 289: 54-65.

Sofuoglu M, Dudish-Poulsen S, Nelson D, Pentel PR, Hatsukami DK (1999). Sex and menstrual cycle differences in the subjective effects from smoked cocaine in humans. Exp Clin Psychopharmacol 7: 274-283.

Sorg BA, Davidson DL, Hochstatter T, Sylvester PW (2002). Repeated cocaine decreases the avoidance response to a novel aversive stimulus in rats. Psychopharmacology 163: 9-19.

Stöhr T, Wermeling DS, Weiner I, Feldon J (1998). Rat strain differences in open-field behavior and the locomotor stimulating and rewarding effects of amphetamine. Pharmacol Biochem Behav 59: 813-818. 
Thompson TL, Moss RL (1994). Estrogen regulation of dopamine release in the nucleus accumbens: genomic- and nongenomicmediated effects. J Neurochem 62: 1750-1756.

Toney TW, Pawsat DE, Fleckenstein AE, Lookingland KJ, Moore KE (1992). Evidence that prolactin mediates the stimulatory effects of estrogen on tuberoinfundibular dopamine neurons in female rats. Neuroendocrinology 55: 282-289.

van Luijtelaar EL, Dirksen R, Vree TB, van Haaren F (1996). Effects of acute and chronic cocaine administration on EEG and behaviour in intact and castrated male and ovariectomized and intact female rats. Brain Res Bull 40: 43-50.

VanVugt DA, Heisler LE, Reid RL (1992). Progesterone inhibits the estrogen-induced gonadotropin surge in the rhesus monkey independent of endogenous opiates. J Clin Endocrinol Metab 74: 1312-1319.

Walker QD, Cabassa J, Kaplan KA, Li S-T, Haroon J, Spohr HA et al (2001). Sex differences in cocaine-stimulated motor behavior: disparate effects of gonadectomy. Neuropsychopharmacology 25: 118-130.

Wildt L, Hutchison JS, Marshall G, Pohl CR, Knobil E (1981). On the site of action of progesterone in the blockade of the estradiol-induced gonadotropin discharge in the rhesus monkey. Endocrinology 109: 1293-1294.

Zhou W, Cunningham KA, Thomas ML (2002). Estrogen regulation of gene expression in the brain: a possible mechanism altering the response to psychostimulants in female rats. Mol Brain Res 100: 75-83. 